\title{
Association Between Sense of Coherence and Metabolic Control in People with Diabetes Mellitus Type 2
}

\author{
Mónica Susana Guevara C, RND, Msc
}

Escuela de Gastronomía, Facultad de Salud Pública, Escuela Superior

Politécnica de Chimborazo ESPOCH, Ecuador

Marcelo Nicolalde, MD, MA

Escuela de Nutrición y Dietética, Facultad de Salud Pública, Escuela

Superior Politécnica de Chimborazo ESPOCH, Ecuador

Amparo Amoroso, MD, Msc

Hospital IESS Riobamba, Ecuador

Patricia Chico, RND, Msc

Escuela de Nutrición y Dietética, Facultad de Salud Pública, Escuela

Superior Politécnica de Chimborazo ESPOCH, Ecuador

Nicole Mora, Bsc

Escuela de Biotecnología ambiental, Facultad de Ciencias, Escuela Superior

Politécnica de Chimborazo ESPOCH, Ecuador

Susana Heredia, RND, Msc

Escuela de Nutrición y Dietética, Facultad de Salud Pública, Escuela

Superior Politécnica de Chimborazo ESPOCH, Ecuador

Francisco Robalino, $M D$

Hospital General Docente MSP. Riobamba, Ecuador

Gabriela Gonzalez, MD

Hospital IESS Riobamba, Ecuador

Doi: 10.19044/esj.2018.v14n15p90 URL:http://dx.doi.org/10.19044/esj.2018.v14n15p90

\begin{abstract}
The chronic complications of type 2 diabetes mellitus are related to the level of metabolic control and often inadequate control is achieved, so there is the possibility of exploring other therapeutic options. The sense of coherence makes it possible to face several stressors and maintain health. This research aimed to explore whether people with diabetes mellitus 2 and high values in the sense of coherence scale have better metabolic control. Cross-sectional study in patients with diabetes 2 . The value of the coherence sense scale and HbA1c glycosylated hemoglobin was determined. A multivariate analysis was carried out by conglomerates and the average $\mathrm{HbA} 1 \mathrm{c}$ ratio was established for
\end{abstract}


these groups. 163 subjects participated with an average of 59.64 years. Three clusters were identified and classified as High, Medium and Low sense of Coherence. When establishing the relationship with HbA1c it was found that the High Group had an average HbA1c of $6.22 \%$, the middle group $7.24 \%$ and the low group $7.49 \%$ of HbA1c, $\mathrm{p}<.05$. It was identified that a high Sense of Coherence is significantly associated to a better metabolic control given by HB A1c.

Keywords: Sense of coherence, glycosylated hemoglobin, diabetes mellitus 2

\section{Introduction}

The morbidity and mortality due to diabetes mellitus type 2 in the adult population currently represent a serious public health problem. In Ecuador, in people aged 20-79 years, the estimated prevalence of type 2 diabetes mellitus in 2012 was $6.89 \%$ with 5492 annual deaths and an increase of 19,000 cases per year with a cost of care of approximately 1891 million dollars. (Freire WV, 2013; Wild S, 2000; INEC, 2013; Zemmet P, 2001)

Diabetes mellitus type 2 is associated with the development of chronic complications, it is very common to find type 2 diabetics who, despite having an adequate and often rigid schedule of pharmacological treatment, do not achieve good metabolic control, (Ahola A, 2010; Amelang, 1997). This situation opens the possibility of exploring other therapeutic options, not necessarily pharmacological, that could contribute to better control of patients with type 2 diabetes mellitus (Antonovsky, 1987;Feldt T, 2005).

In interventions that require self-care to increase their efficacy, values, norms, beliefs, practices, experiences and culture of the environment must be taken into account, there must be a solid understanding of the effect of psychosocial stressors and support systems, it is considered that this aspect may be a good option to improve metabolic control in type 2 diabetic patients (Group, 1993; Surtees P, 2003)

Aarón Antonovsky, American-Israeli sociologist in the eighties conducted research on stress and its effects on health and developed the Sense of Coherence theory, SOC, He considered that the health of an individual is related to the SOC, which together with the generalized sources of resilience, enables the individual to adequately address several stressors for the maintenance of health. Thus, the stronger a person's SOC is, the more likely he or she will be able to adopt appropriate strategies of control, self-care, maintaining healthy habits, and a good level of adherence to medical indications (Antonovsky, 1987; Lindmark U, 2005; Ahola A, 2010).

Individuals with low values on the SOC scale report having a higher frequency of several chronic diseases such as obesity, insulin resistance and type 2 diabetes mellitus and little ability to change unhealthy eating habits. It 
has been found that better control of blood glucose levels, glycosylated hemoglobin A1c and atherogenic dyslipidemia index in type 1 diabetics are associated with high values in the SOC scale. Therefore, interventions to improve SOC in general or any of its aspects, if they exist, could be important for a better metabolic control of patients with diabetes mellitus and thus reduce the incidence of chronic complications (Surtees P, 2003; Lindmark U, 2005; Ahola A, 2010). The present study proposes to evaluate the relationship between the levels of the sense of coherence scale (SOC) that individuals with type 2 diabetes mellitus have and the level of metabolic control measured, to propose, if a positive relationship is found, actions aimed at improving the capacity or sense of coherence.

\section{Subjects nd methods}

A cross-sectional non-experimental design study was carried out that measures only once and at the same time the explanatory variable, the result, and the control variables. The protocol of the present investigation was approved by the institutional review committee of the IESS Hospital, the Research Institute, IDI, of the Polytechnic Higher School of Chimborazo and peer institutional evaluators, observing the ethical principles of the Declaration of Helsinki of the World Medical Association.

Source population: Outpatient patients of the IESS and General hospitals of the City of Riobamba 2015-2016. Eligible population: People with diabetes mellitus type 2 who gave their informed consent to participate in the study and who attended scheduled outpatient consultation. Participating population: Sample of 163 participants, non-randomized, estimated with a 95\% confidence level, prevalence of $7.3 \%$ and accuracy of 3.3\%. Measurements: Age in years of age, weight, height, Body Mass Index BMI, Sense of Coherence, SOC, was measured by the Questionnaire of Life Orientation of 29 questions filled by the participants after an explanation and supervision by health personnel. The biochemical determinations were made in a same venous blood sample which was taken under basal conditions and after eight hours of fasting in the central laboratory of the IESS Riobamba Hospital. The glycosylated hemoglobin A1c as a measure of metabolic control was determined by immuno-turbidimetric test, a standardized test based on the reference method approved by the IFCC. The test has a measuring range of 3$26 \%$ according to DCCT / NGSP (15-150 mmol / mol of HbA1c according to IFCC) the test is indicated for a total hemoglobin concentration of $6-26 \mathrm{~g} / \mathrm{dl}$ (Reaven, 2004; Gaziano JM, 1997; Quijada Z, 2008; Li C, 2008; MurguíaRomero M, 2013; González-Chávez A, 2011; De Giorgis T, 2013; Caballero, 2014; Kim-Dorner SJ , 2010; Bernabe, 2009).

Analysis. Descriptive statistics were made for all the variables under study according to the measurement scale. The result variable: Glycosylated 
hemoglobin A1c did not have a normal distribution, coefficient of asymmetry 1.5 and kurtosis 2.13, with $\mathrm{p}$ less than .05 in the normality tests of Kolmogorov-Smirnov and Shapiro-Wilk. The different components of the SOC and the total value were calculated, with these values and the values of age and sex, a multivariable cluster analysis was performed by K-means for three groups, this number presented the most balanced proportion of subjects in each group (Quijada Z, 2008). The formation of clusters allowed us to find a group structure with respect to the different combinations that each individual can have of SOC components and use them as a single variable in the analysis with glycosylated hemoglobin. The non-parametric KruskalWallis test was performed to differentiate HbA1c medians between groups or SOC clusters, establishing as significant differences the p-value of the test less than .05 (Tibshirani R, 2001; Motulsky; De la Fuente 2015).

\section{Results}

163 people with type 2 diabetes mellitus who attended the outpatient clinic of the IESS and General Hospitals of Riobamba in the 2015-2016 period were evaluated, of which $66.7 \%$ were men and $33.3 \%$ were women. The age of the participants was between 33 and 81 years with an average of 59.64 (ds 9.5). The body mass index had values between 19.8 and 46.4 with an average of 30.25 and ds 5.19 .

The score obtained in the scale of the sense of coherence was analyzed (table 1), as a total score and for each of its components, following the point assignment scheme proposed by the author, each question uses a Likert scale with values between 1 and 7 for the extremes; never and very often.

Table 1 .Score on the SOC scale and its components in the population studied.

\begin{tabular}{lccccl}
\hline Component & Range & Minimum & Maximum & Average s & \\
\hline $\begin{array}{r}\text { Comprehension } \\
13.2\end{array}$ & 63 & 12 & 75 & 48.7 & \\
$\begin{array}{r}\text { Management } \\
9.0\end{array}$ & 38 & 22 & 60 & 40.6 & 38.2 \\
$\begin{array}{l}\text { Meaning } \\
10.2\end{array}$ & 47 & 9 & 56 & 127 & 68 \\
Total & 135 & 50 & 18.5 & & \\
\hline
\end{tabular}

The sum of the ordinal scale of the SOC in each of the 29 questions was considered as a continuous variable, according to the original questionnaire there is a group of questions in which the value assigned to the calculations is the inverse scale.

The average total SOC value for men was 124.9 and women 129.0 these differences were not statistically significant when performing a t test for independent samples $(\mathrm{p}=.339)$. The age and the value of the total SOC had a 
very low correlation, although significant, with a coefficient of determination $\mathrm{r} 2=.029$, that is to say, the older a higher SOC is expected although the influence is minimal. Sex and age, therefore, were not subsequently taken as control variables.

Three clusters or clusters (table 2), were identified and classified as high, medium and low SOC, according to the average values of the components and the total SOC. A description was made of the structure of the groups and the behavior of the variables within them and in comparison, with others, as expected after a classification by clusters, the various components had statistically significant differences between groups.

Table 2. Average values of SOC components by clusters or clusters in the population studied.

\begin{tabular}{|c|c|c|c|c|}
\hline \multicolumn{2}{|c|}{ Comprehension } & Management & meaning Total & \\
\hline Cluster 1 (n) & & & & \\
\hline $\begin{array}{l}\text { SOC HIGH (32) } \\
\text { Cluster } 2 \text { (n) }\end{array}$ & 67,8 & 52,0 & 50,5 & 170,6 \\
\hline $\begin{array}{l}\text { SOC MEDIUM (94) } \\
\text { Cluster } 3 \text { (n) }\end{array}$ & 48,5 & 40,3 & 36,3 & 127,0 \\
\hline SOC LOW (37) & 34,6 & 30,0 & 27,4 & 92,1 \\
\hline
\end{tabular}

The location by clusters to the population studied allowed to evaluate the three components of the SOC and the total at the same time and thus find a better structure of the relationship with the response variable.

Using the Kruskal-Wallis test for median differences between study groups according to SOC, the relationship between the variable related to metabolic control, glycosylated hemoglobin A1c, of people with type 2 diabetes mellitus was evaluated. In this analysis it was found that the glycosylated hemoglobin had clinical and statistically significant differences $(\mathrm{p}=.006)$ in each conglomerate (graph 1). So it is established that there is a significant association between the sense of coherence proposed by Antonovsky and the level of metabolic control achieved by people with diabetes mellitus 2, thus, the higher the sense of coherence the lower the level of glycosylated hemoglobin A1c and, therefore, better metabolic control.

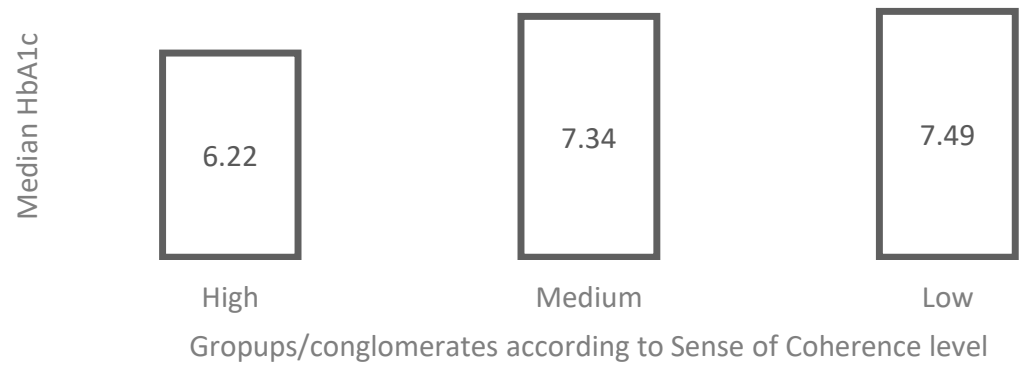

Figure 1. Relationship between levels of soc and glycosilated hemoglobin a1c 


\section{Discussion}

A significant association was found between SOC levels and metabolic control measured by glycosylated hemoglobin A1c, with glycosylated hemoglobin values being $7.49 \%$, in people with a low SOC and $6.22 \%$ in people with high SOC, this result would indicate that there is a therapeutic possibility or possible gap for new actions that help to improve metabolic control and would have to do with the general orientation towards life, its understanding, management and meaning, a field not very explored to date.

The relationship found is probably due to the fact that the metabolic control of people with diabetes mellitus type 2, like many other chronic diseases, requires a large percentage of self-care and this in turn depends on many factors related to the individual and its form to see life itself, it conditions the way in which stressors are understood, their meaning, the possibility of facing them and the value or utility of doing so, which is ultimately the sense of coherence SOC. It is important to emphasize that the SOC refers to tools for life in general and should not be confused with diabetic education, they are two totally different aspects and it is necessary to understand and differentiate them.

The questionnaire used to evaluate the SOC has been validated internationally and in different cultural contexts it has been found to have high internal and external validity. The questionnaire of 29 questions was used, although there are other versions with a smaller number of questions and with modifications, considering that it was originally proposed by the author and the most complete. An important difficulty of the present study was the system of assignment of the subjects, non-random proposition as would be ideal, although a population representativeness is not needed but a specific group of people and that justifies the type of sample used.

The results obtained in this research are similar to those obtained by other authors, especially the work of Ahola performed in people with diabetes mellitus type 1, who find an average glycosylated hemoglobin of $8.1 \%$ in people with high SOC, many authors use different variables effect or result, most metabolic control, and analyze the correlation with each component of the SOC in this way the analysis is difficult, our proposal to first identify clusters with the SOC components was very useful and facilitated the analysis. (Ahola A, 2010; Lindmark U, 2005; Quijada Z, 2008).

\section{Conclusion}

The relationship found between the SOC and the metabolic control measured by the HBA1c allows us to explore the possibility, if any, of improving the SOC of people and thus achieve a better metabolic control to reduce chronic complications and mortality. 


\section{References:}

1. Ahola A, S. M. (2010). 5. Ahola A, SaraheiThe cross-sectional associations between sense of coherence and diabetic microvascular complications, glycaemic control, and patients'conceptions of type 1 diabetes mellitus. Health and Quality of Life Outocomes, 8/142.

2. Amelang, M. (1997). Using personality variables to predict cancer and heart disease. Eur J Pers, 11:319-342.

3. Antonovsky, A. (1987). Unraveling the mystery of health: how people manage stress and stay well. San Francisco: Jossey-Bass.

4. Bernabe, E. K.-T. (2009). 1. Bernabe, E. Kivimáki, M. Tsakos, G. Suaminen- Taipale, Al. S"the relationshionship among sense of coherence, socio-economic status, and oral health-related behaviours among Finnish dentate adults . Eur J Oral Sci, 117: 413-418.

5. Caballero, R. (2014). Epidemiología de la dislipidemia aterogénica en un área urbana de la ciudad de Barcelona. Clin Invest Aterioscl, 26 (1): 17-9.

6. De Giorgis T, M. M. (2013). 23Triglycerides-to-HDL ratio as a new marker of endothelial dysfunction in obese prepubertal children. Eur J Endocrinol, 170(2): 173-80.

7. De la Fuente, S. (s.f.). Análisis conglomerados. Madrid. Universidad Autónoma de Madrid. Recuperado el 13 de Febrero de 2015, de De la Fuente S. Análisis conglomerados. Madrid. Universidad Auhttp:// www.fuenterrebollo. Com /Economicas/ Econometría/ Segmentación/ Conglomerados/ conglomerados.pdf

8. Feldt T, K. K. (2005). The role of family background, school success, and career orientation in the development of sense of coherence. European Psychologist, 10:298-308.

9. Freire WV, R. M. (2013). 2. Freire WV, Ramírez MJ, Belmont P, MendResumen Ejecutivo Tomo 1 Encuesta Nacional de Salud y Nutrición del Ecuador. ENSANUT-ECU 2011-2013. Recuperado el 16 de Marzo de 2015, de 2. Freire WV, Ramírez MJ, Belmont P, Mendieta MJ, Silva MK,Romero N, et al. 2013. Resumen Ejecutivo Tomo 1 Encuesta Nacional de Salud y Nutrhttp://instituciones.msp.gob.ec/imagenes/Documentos/varios/EN SANUT.pdf

10. Gaziano JM, H. C. (1997). Gaziano JM, HenneFasting triglycerides, high-density lipoprotein, and risk of myocardial infarction. Circulation, 96(8): 2520-5.

11. González-Chávez A, S.-M. L.-A. (2011). Elevated triglycerides/HDLcholesterol ratio associated with insulin resistance. Cir Cir, 79(2): 12631 . 
12. Group, T. D. (1993). The Diabetes Mellitus Control and ComplicatioThe effect of intensive treatment of diabetes mellitus on the development and progression of long-term complications in insulin-dependent diabetes mellitus mellitus. The Diabetes Mellitus Control and Complications Trial Research Group. "The effect of intensive treatment of diabetes mellitus on the develoN Engl J Med, 329: 977-986.

13. INEC. (2013). Anuario de estadistidisticas vitales: nacimientos y defunciones. Recuperado el 16 de Marzo de 2015, de www.ecuadorencifras.gob. ec/documentos/web-inec/Población y Demografia/ Nacimientos Defunciones/Publicaciones/

14. Kim-Dorner SJ, D. P. (2010). Should triglycerides and the triglycerides to high-density lipoprotein cholesterol ratio be used as surrogates for insulin resistance? Metabolism, 59(2): 299-304.

15. Li C, F. E. (2008). Does the association of the triglyceride to highdensity lipoprotein cholesterol ratio with fasting serum insulin differ by race/ethnicity? Cardiovasc Diabetol, 7: 4.

16. Lindmark U, S. B. (2005). Food selection associated with sense of coherence in adults. Nutr $J, 28: 9$.

17. Motulsky, H. (s.f.). Prism 5 Statistics Guide. GraphPad Software inc.San Diego CA. Obtenido de www.graphpad.com.

18. Murguía-Romero M, J.-F. J.-F.-C.-M. (2013). Murguía-Romero M, Jiménez-Flores JR, Sigrist-Flores Plasma triglyceride/HDLcholesterol ratio, insulin resistance, and cardiometabolic risk in young adults. Murguía-Romero M, Jiménez-Flores JR, Sigrist-Flores SC, Espinoza-Camacho MA, Jiménez-Morales M, Piña E, et al. Plasma J Lipid Res, 54(10): 2795-9.

19. Quijada Z, P. M. (2008). Quijada Z, Paoli M, Zerpa The triglyceride/HDL-cholesterol ratio as a marker of cardiovascular risk in obese children; association with traditional and emergent risk factors. Quijada Z, Paoli M, Zerpa $Y$, Camacho $N$, Cichetti $R$, Villarroel $V$, et al. The triglyceride/HDL-cholesterol ratio as a marker of cardiovascular Pediatr Diabetes mellitus, 9(5): 464-71.

20. Reaven, G. (2004). Insulin Resistence, Carciovascular Disease, and the Metabolic Syndrome. Diabetes mellitus Care, 27(4): 1011-2.

21. Surtees P, W. N. (2003). Sense of coherence and mortality in men and women in the EPICNorfolk United Kingdom prospective cohort study. Surtees $P$, Wainwright $N$, Luben R, Khaw KT, Day NE: Sense of coherence and mortality in meAm J Epidemiol, Surtees P, Wainwright $\mathrm{N}$, Luben R, Khaw KT, Day NE: Sense of coherence and mortality in men an158:1202-1209. 
22. Tibshirani R, W. G. (2001). Estimating the number of clusters in a date set via the gap statistic. J R Statist Soc, 63(2): 411-23.

23. Wild S, R. G. (2000). 4Global prevalence of diabetes mellitus: estimates for the year 2000 and projections for 2030. 2004. 4. Wild S, Roglic G, Green A, Sicree R, King H: Global prevalence of diabetes mellDiabetes mellitus Care, 27:1047-1053.

24. Zemmet P, A. K. (2001). Global and societal implications of the diabetes mellitus epidemic. Nature, 414:782-787.

\section{Appendix}

\section{Orientation to Life Questionnaire}

Here is a series of questions relating to various aspects of our lives. Each question has seven possible answers. Please mark the number which expresses your answer, with number 1 to 7 being the extreme answers. If the words under 1 are right for you, circle 1; if the words under 7 are right for you, circle 7 . If you feel differently, circle the number which best expresses your feeling. Please give only one answer to each question.

1. When you talk to people, do you have the feeling that they don't understand you? 1 never have this feeling 234567 always have this feeling

2. In the past, when you had to do something which depended upon cooperation with others, did

you the feeling that it:

1 surely wouldn't get done 234567 surely would get done

3 . Think of people with whom you come into contact daily, aside from the ones to whom you feel closest. How well do you know most of them?

1 you feel that they are strangers 234567 you know them very well 4. Do you have the feeling that you don't really care about what goes around you?

1 very seldom or never 234567 very often

5. Has it happened in the past that you were surprised by the behavior of people whom you thought you knew well?

1 never happened 234567 always happened

6. Has it happened that people whom you counted on disappointed you?

7. Life is:

1 never happened 234567 always happened

1 full of interest 234567 completely routine 
8. Until now your life has had:

1 no clear goals or purpose at all 234567 very clear goals and purpose

9. Do you have the feeling that you're being treated unfairly?

1 very often very 234567 seldom or never

10. In the past ten years your life has been:

1 full of changes 234567 without consistent knowing what will happen next

11. Most of the things you do in the future will probably be:

1 completely fascinating2 34567 deadly boring

12. Do you have the feeling that you are in an unfamiliar situation and don't know what to do?

1 very often 234567 very seldom or never

13. What best describes how you see life:

1 one can always find a solution to painful things in life 234567 there is no solution to painful things in life

14. When you think about your life, you very often:

1 feel how good is it to be alive 234567 ask yourself why you exist at all 15. When you face a difficult problem, the choice of a solution is:

1 always confusing and hard to find 234567 always completely clear 16. Doing the things you do everyday is: boredom

1 a source of deep pleasure and satisfaction 234567 a source of pain and

17. Your life in the future will probably be:

1 full of changes without your knowing what will happen next 234567 completely consistent and clear

18. When something unpleasant happened in the past your tendency was:

1 "to eat yourself up" about it 234567 to say "ok, that's that, I have to live with it" and go on

19. Do you have very mixed up feelings and ideas?

1 very often 234567 very seldom or never

20. When you do something that gives you a good feeling: 
1 it's certain that you'll go on feeling good 234567 it's certain that something will happen to spoil the feeling

21. Does it happen that you have feelings inside you would rather not feel?

1 very often 234567 very seldom or never

22. Do you anticipate that your personal life in the future will be:

1 totally without meaning and purpose 234567 full of meaning and purpose 23. Do you think that there will always be people whom you'll be able to count on in the future?

1 you're certain there will be 234567 you doubt there will be

24. Does it happen that you have the feeling that you don't know exactly what's about to happen?

1 very often 234567 very seldom or never

25. Many people - even those with a strong character - sometimes feel like sad sacks (losers) in

certain situations. How often have you felt this way in the past?

1 never 234567 very often

26. When something happened, have you generally found that:

1 you overestimated or understimated its importance 234567 or you saw things in the right proportion

27. When you think of difficulties you are likely to face in important aspects of your life, do you

have the feeling that:

1 you will always succeedin the difficulties 234567 you won't succeed in overovercoming

coming the difficulties

28. How often do you have the feeling that there's little meaning in the things you do in your daily

life?

1 very often 234567 very seldom or never

29. How often do you have feelings that you're not sure you can keep under control?

1 very often 234567 very seldom or never 